\title{
AS MINORIAS COMO O NEGATIVO, O MOVIMENTO DAS MULHERES E O ESPAÇO DIGITAL
}

\author{
Deborah Christina Antunes ${ }^{1}$
}

\begin{abstract}
Resumo:
A partir da importância dada pelos teóricos da Escola de Frankfurt aos grupos que são sistematicamente perseguidos, e ao mesmo tempo, do reconhecimento de que sua existência se realiza como uma função específica de manutenção da sociedade burguesa, como parte da dialética de sua existência, realizamos aqui um estudo empírico inspirado na ideia da necessidade de mergulharmos nos detalhes concretos para compreender a realidade e, desse modo, ter a possibilidade de operar transformações efetivas em sua base. Trata-se de análises realizadas a partir de um debate de um grupo feminista no Facebook, em busca de suas possibilidades emancipadoras, adentrando na esfera de uma tradição mais empírica dos estudos em Teoria Crítica, sem deixar de lado a reflexão conceitual.
\end{abstract}

Palavras-chave: Minorias; Negativo; Feminismo; Theodor W. Adorno; Herbert Marcuse.

\section{MINORITIES AS THE NEGATIVE, THE WOMEN'S MOVEMENT AND DIGITAL SPACE}

\begin{abstract}
:
From the importance given by the theorists of the Frankfurt School to groups that are systematically persecuted, and at the same time from the recognition that their existence is realized as a specific function of maintaining bourgeois society, as part of their inner dialectic, we realize here an empirical study inspired by the idea of the need to delve into the concrete details to understand reality and, thus, to have the possibility to operate effective transformations at its base. These are analyzes made from a debate of a feminist group on Facebook, in search of their emancipatory possibilities, entering into the sphere of a more empirical tradition of studies in Critical Theory, without leaving aside the conceptual reflection.
\end{abstract}

Keywords: Minority; Negative; Feminism; Theodor W. Adorno; Herbert Marcuse.

Para Herbert Marcuse, mulher honorária.

Na primavera de 1956, Horkheimer e Adorno planejaram escrever em conjunto uma nova versão do Manifesto Comunista, de Marx e Engels. A certa altura dos diálogos que foram registrados por Gretel Adorno, Horkheimer afirmou categoricamente: "nós somos a favor do caótico, daquilo que não foi incluído" (Adorno \& Horkheimer, 2011, p.27); Embora Adorno

1 Psicóloga (Unesp/Bauru), mestre em Educação e doutora em Filosofia (UFSCar), com período sanduíche na Universidade da Califórnia Berkeley. Professora Adjunta da Universidade Federal do Ceará, campus Sobral e do Programa de Pós-Graduação em Psicologia (UFC Fortaleza). Autora de "Por um conhecimento sincero no mundo falso: Teoria Crítica, Pesquisa Social Empírica e The Authoritarian Personality" (Paco Editorial, 2014). Bolsista produtividade da Fundação Cearense de Apoio ao Desenvolvimento Científico e Tecnológico - FUNCAP (BPI 09/2018 - processo n. BP3-0139-00147.01.00/18). E-mail: deborahantunes@ gmail.com. 
discorde da palavra "caótico" com receio de sua ampla defesa, Horkheimer aponta para a ideia de que o não incluído supostamente preserva a si mesmo apaixonado - embora não se saiba até que ponto essa paixão de fato possa negar a sociedade burguesa de modo radical. Nesse momento, ele traz à baila novamente a importância dada, por esses teóricos críticos, não à figura idealizada de um proletariado que se auto libertaria, mas àqueles grupos que são sistematicamente perseguidos - estando empregados ou não - ao mesmo tempo que sua existência se realiza como uma função específica de manutenção da sociedade burguesa.

Se os hegelianos de esquerda, que produziram suas análises em uma época de modernização capitalista da Alemanha, perceberam o proletariado como uma nova força negativa (revolucionária) que poderia realizar sua filosofia, os frankfurtianos vivenciaram exatamente o oposto: o enfraquecimento da classe trabalhadora como potência revolucionária. (Jay, 2008). Isso porque, para Horkheimer (1986), ela estava dividida entre trabalhadores que se sentiam plenamente integrados - e, portanto, teriam algo a perder - e aqueles que permaneceram fora do mercado de trabalho, mas que não tinham qualquer ideia de formas possíveis de organização. Horkheimer reconhece que "a miséria dos trabalhadores continua sendo a condição e o fundamento dessa forma de sociedade; mas o tipo de trabalhador já não é mais daquele que necessita de uma transformação urgente" (p.87).

Tendo uma vida dedicada à luta das minorias como uma resposta estrutural intelectual e política à dinâmica da violência, da supremacia branca, do patriarcado, do poder estatal, do mercado capitalista e das políticas imperialistas, em 2015, Angela Davis (2016) retomou essa ênfase de modo amplo quando apontou que o movimento dos imigrantes e refugiados seria o movimento de nosso século; ele denuncia globalmente o racismo, o genocídio, o colonialismo. Para além dos campos de concentração, genocídio é compreendido desde o final da Segunda Guerra Mundial, como todo ato cometido com a intenção de destruir, no todo ou em parte, um grupo religioso, racial, étnico, nacional. Isso inclui assassinato, espancamento, assédio moral, imposição de métodos contraceptivos, e marginalização no acesso às condições de sobrevivência de membros desses grupos, no intuito de acabar com eles existencialmente. (Davis, 2016). O colonialismo, por sua, vez, refere-se às conquistas imperialistas que se expandiram nos diversos continentes, como América, Ásia e África, que “submeteram populações nativas inteiras, incorporando-as à sua organização estatal através da superioridade bélica" (Chaves, 1971, p.151), bem como a transferência de grupos populacionais contra seu próprio interesse e para fins de exploração. As minorias, embora muitas vezes

\begin{tabular}{|l|c|c|c|c|}
\cline { 2 - 5 } & Ano 8 & n. 14 & Janeiro - Julho 2019 & p. $213-234$ \\
\hline
\end{tabular}


quantitativamente superiores, são caracterizadas por uma relação de dominação e descriminação.

Não é por acaso que o estudo do preconceito marca uma das maiores pesquisas empíricas realizadas por Adorno, "A personalidade autoritária" herdeira dos estudos anteriores que enfocaram o caráter autoritário existente nas classes trabalhadoras - como "A classe trabalhadora na Alemanha de Weimar", de Erich Fromm realizado no final da década de 1920, e "Autoridade e Família", coordenado por Horkheimer no início da década de 1930. O preconceito e suas estereotipias, resultantes das condições objetivas de uma vida orientada pela escassez e pelo medo, pela destruição e pela dominação, se apresentam com uma função psicológica e social que marca profundamente as subjetividades: trata-se de um modo de orientação em um mundo já caótico e incompreensível, e também uma forma de tentar manter os, poucos é verdade, privilégios (supostamente) adquiridos dentro de uma organização social incapaz de garantir a existência daqueles que a ela pertencem (ou que são ditos pertencer) apesar dos chamados avanços tecnológicos. Exatamente por isso, o preconceito denuncia a existência de algo "ameaçador" naqueles que, via de regra, são reconhecidos como pertencentes a grupos específicos. Judeus, negros, deficientes, homossexuais, ciganos eram presos em campos de concentração nazistas. Judeus, negros, armênios, orientais, latinos e latinoamericanos, indígenas eram alvos de preconceitos nos Estados Unidos no mesmo período, e historicamente.

Havia uma placa nas praias de Nova Iorque, em meados do século XX, assim como em outros lugares América afora, onde lia-se: "proibido cachorros, negros e judeus", outras versões traziam: "proibido cachorros, negros e mexicanos". Dizia-se que negros e judeus tinham um cheiro ofensivo (Adorno et al, 1969). Mulheres ainda hoje são culpadas pelas violências que vivenciam, apontando que há algo nelas passível de provocar/ofender o outro. Lembro Horkheimer e Adorno (1985, p. 161) nos "Elementos do Antissemitismo" da Dialética do Esclarecimento,

[...] costumes estranhos que lembram a terra prometida, a beleza que lembra o sexo, o animal execrado como repugnante porque provoca a promiscuidade), tudo isso atrai sobre si o desejo de destruição dos civilizados que jamais puderam realizar totalmente o doloroso processo civilizatório. Os que exercem um domínio crispado sobre a natureza veem na natureza atormentada o reflexo provocante da felicidade impotente.

Sartre, em seu texto sobre a questão judaica, aponta que essa provocação que se sente no corpo, embora, para ele, tenha origem na mente, se coloca de modo tão profundo e completo

\begin{tabular}{|c|c|c|c|c|}
\cline { 2 - 5 } Q Q Dialectus & Ano 8 & n. 14 & Janeiro - Julho 2019 & p. 213-234 \\
\hline
\end{tabular}


que se estende ao reino fisiológico mesmo, tal como ocorre na histeria (Sartre, 1966, p.11); e a histeria, como coloca Lacan (1992), é o domínio do que não pode ser deflorado, do que não faz parte do discurso normativo, hegemônico do que é, do que existe.

O medo e sua transferência inconsciente fazem parte de uma relação complexa entre o medo do "estranho" e seu preenchimento por um imaginário a respeito de um grupo específico (Adorno et al. 1969). Horkheimer e Adorno (1985, p. 170) apontam partir de Freud, que "[...] o que repele por sua estranheza é, na verdade, demasiado familiar. São os gestos contagiosos dos contatos diretos reprimidos pela civilização". A apresentação do medo do estranho pela idiossincrasia não ocorre por acaso. Ela remete a processos e desejos reprimidos na história da civilização que retornam no indivíduo e se expressam como ódio ao diferente, que em verdade é por demais familiar:

[...] a natureza que não se purificou nos canais da ordem conceitual para se tornar algo dotado de finalidade; o som estridente do lápis riscando a lousa e penetrando até a medula dos ossos; o haut goût (gosto intenso) que lembra a sujeira e a putrefação; o suor que poreja a testa da pessoa atarefada; tudo o que não se ajustou inteiramente ou que fira os interditos em que se sedimentou o progresso secular tem um efeito irritante e provoca uma repugnância compulsiva" (Horkheimer; Adorno, 1985, p. 168).

$\mathrm{Na}$ idiossincrasia, determinados órgãos escapam ao domínio do sujeito e obedecem a estímulos biológicos fundamentais; a reação é a recusa e o desprezo imediatos como esquemas arcaicos de auto conservação. Quando Horkheimer e Adorno (1985) discutem essa questão, se referem ao judeu e ao seu princípio de individuação fisionômico, o nariz:

[...] nas ambíguas inclinações dos prazeres do olfato sobrevive ainda a antiga nostalgia pelas formas inferiores da vida, pela união imediata com a natureza ambiente, com a terra e o barro. De todos os sentidos, o ato de cheirar - que se deixa atrair sem objetualizar - é o testemunho mais evidente da ânsia de se perder no outro e com ele se identificar. Por isso o cheiro, tanto como percepção quanto como percebido (ambos se identificam no ato), é mais expressivo do que os outros sentidos. Ao ver, a gente permanece quem a gente é, ao cheirar, a gente se deixa absorver. É por isso que a civilização considera o cheiro como uma ignomínia, como sinal das camadas sociais mais baixas, das raças inferiores e dos animais abjetos. (Horkheimer; Adorno, 1985, p. 171-172).

A neurociência explica isso: o sentido do olfato é o único que, através dos neurônios genuínos presentes nos receptores olfativos, penetra diretamente e sem intermediários nos cérebros reptiliano e límbico, os mais primitivos de nosso sistema nervoso central e responsáveis pela auto conservação, pela sexualidade, pela agressividade. O olfato foi o

\begin{tabular}{|l|l|l|l|l|}
\cline { 2 - 5 } & Ano 8 & n. 14 & Janeiro - Julho 2019 & p. $213-234$ \\
\hline
\end{tabular}


primeiro meio de acesso ao mundo externo das criaturas primitivas. (Ribas, 2006). Cheiros evocam memórias de forma instintiva e emocional, desafiando aqueles que caracterizam sua espécie pelo desenvolvimento do neocortex, da habilidade cognitiva e intelectual, pela pura racionalidade e astúcia. Lidar com o desconhecido, com o incontrolável em nós - embora nosso, embora familiar - é por demais angustiante. Daí o desejo de destruir esse outro que denuncia em mim aquilo com o qual já não posso lidar. Como é possível ao homem civilizado, moldado a partir de conceitos e certezas fixos e invariáveis permitir-se mover para o oposto, para uma experiência incerta que os conceitos não alcançam? E não é essa justamente a proposta de Adorno em sua Dialética Negativa, a de que possamos nos mover em relação ao não conceitual, ainda que através dos conceitos, mas sem reduzir o não conceitual a conceitos? O movimento em direção àquilo que não pode ser abarcado pelos conceitos é o negativo da dialética adorniana. O conceito, a racionalidade na qual ele emerge, jamais apreenderá seu objeto particular. Este também jamais preencherá seu conceito nesta forma de organização social, no entanto: "A emancipação da sociedade [relativamente ao antissemitismo] depende da possibilidade de elevar ao conceito o conteúdo da idiossincrasia e de tomar consciência de seu absurdo" (Horkheimer; Adorno, 1985, p. 168).

Peço licença para uma digressão conceitual.

$* * *$

Adorno compreende que o conceito é sempre, em alguma medida, diverso do que está subsumido nele. Tanto em seu curso, quanto em seu livro Dialética Negativa, ele $(2009 ; 2010)$ explica que, na lógica dialética, quando B é definido como um A ele é também diferente de e mais do que A, o conceito sob o qual ele está subsumido por meio de um julgamento predicativo. Assim, por exemplo, o conceito de liberdade contém um ponteiro em direção a algo que vai além daquelas liberdades individuais, sem que se compreenda o que é exatamente esse elemento adicional. O conceito é sempre mais e menos do que os elementos incluídos nele:

O juízo de que alguém é um homem livre refere-se, pensando de maneira enfática, ao conceito de liberdade. Esse conceito, contudo, é por sua vez mais do que aquilo que é predicado desse homem, tanto quanto todo homem, por meio de outras determinações, é mais do que o conceito de sua liberdade. Seu conceito não diz apenas que podemos aplica-lo a todos os homens singulares definidos como livres. Aquilo que nutre esse conceito é a ideia de um estado no qual os singulares teriam qualidades que não poderiam ser atribuídas aqui e agora a ninguém. Dizer que alguém é livre tem sua especificidade no sous-entendu (implícito) de que lhe é atribuído algo impossível porque esse algo se manifesta nele; esse elemento que ao mesmo tempo salta aos olhos e é secreto anima todo juízo identificador que de alguma maneira é válido. O conceito de liberdade fica aquém de si mesmo no momento em que é aplicado empiricamente. Ele mesmo deixa de ser então o que ele diz. No entanto, precisa ser confrontado com isso. Uma tal confrontação o conduz a uma contradição consigo mesmo. (ADORNO, 2009, p. 131).

\begin{tabular}{|l|l|l|l|l|}
\cline { 2 - 5 } & Ano 8 & n. 14 & Janeiro - Julho 2019 & p. $213-234$ \\
\hline
\end{tabular}


O segundo significado do elemento de contradição concerne à preocupação com a natureza contraditória do próprio objeto, da realidade. Assim, a essência do modelo de sociedade antagônica na qual se vive é que ela não é uma sociedade com contradições ou a despeito de suas contradições, mas sim em virtude de suas contradições. A sociedade baseada no lucro produz sua própria existência. O princípio de dominação da natureza se estende e permanece na dominação dos homens pelos homens; seu reflexo mental é o princípio da identidade que atrai para sua esfera de influência toda alteridade que lhe é apresentada. Tratase de uma contradição imanente, que constitui a natureza do próprio objeto: "a dialética é negativa em virtude da negatividade de seu objeto" (ADORNO, 2010, p. 165); por isso, ela depende da comprovação dessa negatividade, não podendo ser aplicada a ele, de fora. Por outro lado, a própria primazia do objeto deve ser, a todo tempo, também comprovada:

\begin{abstract}
A possibilidade de uma Dialética Negativa depende da prova da primazia do objeto. Ela também não pode ser um princípio absoluto para a dialética ou uma retomada de um realismo ingênuo: ela é válida apenas na inter-relação. Se a primazia do objeto se libertasse da dialética e fosse postulada de forma positiva - acompanhada pelos uivos triunfantes da cumplicidade - então a filosofia regressaria ao dogma estúpido da reprodução ou reflexo da realidade [...]. Novamente, um princípio, uma "máxima", seria hipostasiada e o pensamento reduziria tudo que existe a um denominador comum. (ADORNO, 2010, p. 200).
\end{abstract}

Desses dois significados, compreende-se que a necessidade da contradição como elemento central emerge tanto do objeto, quanto do pensamento que, em sua forma de conceito, é incapaz de alcançar a totalidade daquilo a que ele se refere. Um modo de reflexão e análise que a incorpora não é nada além do que um executor, um modo de pensar que se dedica ao que seu material disponibiliza. (ADORNO, 2010). Como Adorno (2003, p. 33) aponta em Ensaio como forma, trata-se de "pensar a coisa, desde o primeiro passo, com a complexidade que lhe é própria, tornando-se um corretivo daquele primitivismo obtuso, que sempre acompanha a ratio corrente".

$* * *$

Há que se admitir aqui, então, certa culpa desses grupos historicamente perseguidos não sem enfatizar que essa culpa é seu maior trunfo. Ou seja, não quero com isso dizer que a supressão da barbárie, ou ainda uma harmonização e um apaziguamento das relações sociais e das contradições da sociedade dependam de uma atitude vorazmente adaptativa às regras do

\begin{tabular}{|l|l|l|l|l|}
\cline { 2 - 5 } & Ano 8 & n. 14 & Janeiro - Julho 2019 & p. $213-234$ \\
\hline
\end{tabular}


jogo. Sartre também nos lembra que nenhuma assimilação basta para se poder estar seguro de pertencer à sociedade.

[...] o judeu dança como os outros a dança da honradez e da respeitabilidade; aliás, ele não é escravo de ninguém, livre cidadão num Estado que autoriza a livre concorrência, nenhuma dignidade social, nenhum cargo do Estado lhe são interditos, ele receberá a Legião de Honra, será grande advogado, ministro. Mas no mesmo momento em que ele chega ao topo da sociedade legal, outra sociedade amorfa, difusa e onipresente mostra-se a ele de relance e se oculta. Ele sente de maneira muito particular a vaidade das honrarias e da fortuna, pois o maior sucesso não lhe permitirá jamais ter acesso a essa sociedade que se pretende verdadeira; ministro, será um ministro judeu, ao mesmo tempo uma excelência e um intocável (Sartre, 1966, p. 79-80).

Parafraseio Sartre: Presidente, será uma presidente(a) mulher. Medalhista, será uma medalhista negra. Professor, será um professor homossexual. Estudante será um estudante indígena, cotista e assim por diante. E não é que essas diferenças apontadas simplesmente fortalecem qualquer identidade, mas seu efeito localiza-se em marca-los como "intocáveis", aqueles que sempre irão pertencer às classes mais baixas, sujas, ignorantes - as dos não civilizados. Embora o preconceito contra as minorias nunca tenha deixado de se manifestar, nos momentos de crise econômica (de sistema), como o que o mundo está vivenciando desde 2008, ele se arrefece: países fecham suas portas para estrangeiros e diminuem a possibilidade de sobrevivência de pobres, negros, mulheres, indígenas e LGBTs ao descontinuar políticas que enfocam ao menos uma tentativa de superação das injustiças sociais - e o fazem como medida de proteção: proteção de uma determinada ordem social contra o não-idêntico. Isso nos diz muito.

Quando Horkheimer e Adorno (1985) fizeram sua análise do antissemitismo, eles apontaram duas doutrinas opostas sobre os judeus, ao mesmo tempo falsas e verdadeiras. A primeira dizia que, para os fascistas, os judeus não são uma minoria, mas sim a anti-raça, o princípio negativo em si mesmo: de sua exterminação dependeria a felicidade de todos. A segunda aponta os judeus como povo livre de características nacionais e raciais, que formaria um grupo baseado na opinião e na tradição. A primeira tese só é verdadeira porque o fascismo a tornou. Vítimas e algozes são intercambiáveis: qualquer um pode tomar o lugar do assassino caso se converta em norma. A multiplicidade das vítimas também deixa entrever que o suposto "fator problemático" do outro é mais universal do que se poderia desconfiar. A segunda, só é verdadeira na Ideia, mas “ao colocar a unidade dos homens como já realizada por princípio, ela ajuda a fazer apologia do existente" (p.158).

\begin{tabular}{|l|c|c|c|c|}
\cline { 2 - 5 } & Ano 8 & n. 14 & Janeiro - Julho 2019 & p. $213-234$ \\
\hline
\end{tabular}


A adaptação, ainda que sempre deficitária, das minorias à lógica do sistema que lhes é imposto reforça a possibilidade de que ao fim e ao cabo elas se identifiquem com o existente o que torna seu conteúdo negativo impotente, na medida em que perpetua a própria sociedade burguesa, ainda que através de sua negação: “o entrelaçamento dialético do esclarecimento e da dominação, a dupla relação do progresso com a crueldade e a libertação, que os judeus tiveram que provar nos grandes esclarecedores bem como nos movimentos populares democráticos, também se mostra no ser dos próprios assimilados" (p.158).

Não é possível afirmar que Adorno acreditava no potencial revolucionário das minorias como algo dado. Na pesquisa sobre a personalidade autoritária ele percebeu que mesmo as minorias já haviam também se identificado com o poder e discriminavam-se entre si, ao invés de se juntarem contra o inimigo comum: haviam membros das minorias com fortes tendências conformistas e abertamente antissemitas, por exemplo. Ali ele parte do

[...] pressuposto de que a - amplamente inconsciente - hostilidade resultante da frustração e da repressão, e socialmente desviada de seu verdadeiro objeto, precisa de um objeto substituto através do qual ele pode obter um aspecto realístico e então esconder, como se diz, as manifestações mais radicais de um bloqueio da relação do sujeito com a realidade (Adorno et al, 1969, p. 607-608).

É preciso assumir a complexidade da existência na sociedade antagônica. Não para fundar um viés pessimista, mas para encontrar possibilidades de superação. Somos ao mesmo tempo as minorias e nossos próprios algozes. Os algozes têm em si mesmo tudo aquilo que negam e acusam nas minorias; embora o equilíbrio de forças em ambos não seja o mesmo. Por isso, elas (nós), como grandes espelhos refletimos a imagem que não se quer ver. Somos tábuas de projeção. Denunciadoras. Aquelas que interrogam, questionam com sua existência verdades anunciadas e por isso apontam para a existência de diferentes possibilidades que não se sabe. E essa é, como um sintoma, marca de uma repressão e uma função libertadora, na medida em que se torna possível compreender e elaborar esse processo. A verdade nunca se pode dizê-la senão pela metade. Lembrando Lacan (2009, p. 23), "A dimensão do sintoma é isso que fala. Fala inclusive com os que não sabem ouvir. E não diz tudo, nem mesmo aos que sabem".

A negação também não deve ser hipostasiada. Ela não é destino nem da classe trabalhadora, nem das diversas minorias, senão o que se faz na luta histórica que se estabelece num jogo de forças internas e externas. Por isso, gostaria de voltar à tese de Horkheimer do início e questionar: quem pode, hoje, ser considerado não incluído? O representante do negativo

\begin{tabular}{|c|c|c|c|c|}
\cline { 2 - 5 } & Ano 8 & n. 14 & Janeiro - Julho 2019 & p. $213-234$ \\
\hline
\end{tabular}


enquanto tal que escapa aos antagonismos da libertação e da dominação? Quem pode hoje, ser considerado incluído? Os sujeitos da história não são pessoas melhores, e aqui eu recordo o Galileu Brechtiano que nos lembra da infelicidade daqueles que buscam seus heróis: nos adaptamos e assimilamos ainda que permaneçamos nas margens, por medo do sofrimento, e não para preservar a salvo uma verdade que porventura carregamos.

\section{Como encontrar saídas ou linhas de fuga?}

É bastante conhecida a tese de que, para Adorno, a possibilidade de emancipação se dá unicamente pela via a arte. A arte seria capaz de, através da experiência estética, libertar o não idêntico. Eu proponho que, para Adorno, é possível construir saídas ou possibilidades emancipatórias pela via da ciência, mas de uma ciência esteticamente orientada, uma vez que ele apresenta em sua Teoria Estética a ideia de que embora arte e ciência não devam ser fundidas “[...] as categorias que são válidas em cada uma não são absolutamente diferentes" (Adorno, 1997, p. 131) e ambas estão aptas a buscar a utopia em virtude da negatividade do material, mas apenas se renunciarem a busca por reconciliação. Assim como na arte, a ciência precisa integrar em si o comportamento estético e negativo de perceber mais nas coisas do que elas são. Ela deve extrair "o fenômeno de sua existência e trazê-lo para a autorreflexão; esta seria a reflexão do que está petrificado nas ciências e não uma ciência especializada localizada para além delas [das coisas]. (p. 262). Essa é a ideia das pesquisas empíricas realizadas por Adorno.

Trago aqui então um estudo empírico inspirado na ideia da necessidade de mergulharmos nos detalhes concretos para compreender a realidade e, desse modo, ter a possibilidade de operar transformações efetivas em sua base. Gostaria de mostrar a vocês algumas análises que fiz a partir de um debate de um grupo feminista, em busca de suas possibilidades emancipadoras. Adentro então, nesse momento, na esfera de uma tradição mais empírica dos estudos em Teoria Crítica existente desde a fundação do Instituto de Pesquisa Social de Frankfurt.

As minorias como o negativo: análise de um diálogo em um grupo feminista no Facebook Caracterização da Amostra

\begin{tabular}{|l|l|l|l|l|}
\cline { 2 - 4 } & Ano 8 & n. 14 & Janeiro - Julho 2019 & p. $213-234$ \\
\hline
\end{tabular}


O diálogo analisado, parte de um trabalho mais amplo que visa a compreender as "novas" subjetividades mediadas e mediadoras pelos/dos meios de comunicação digitais. Ele foi retirado de um grupo feminista com uma página no Facebook, chamada "Feminismo sem demagogia - Original". A página foi escolhida para esse estudo por conta do número de pessoas ativas nela. É a página sobre feminismo que mais tem adeptos ativos dentre os usuários brasileiros dessa rede social virtual: 1.073.217 (Um milhão, setenta e três mil, duzentas e dezessete pessoas) curtem a página. Desses, 821.6 Mil são ativos (90\% mulheres e 10\% homens).

92 milhões de brasileiros acessam o Facebook mensalmente, segundo dados fornecidos pela própria rede social ${ }^{2}-45 \%$ da população brasileira. É importante lembrar que, de acordo com os dados do IBGE no último senso, 54,9\% dos lares brasileiros têm acesso à internet, chegando a 95,4 milhões de pessoas ${ }^{3}$. Dentre as pessoas com acesso à internet no Brasil, a grande maioria frequenta mensalmente essa rede social: $96,44 \%$.

Os dados estatísticos disponibilizados pelo Facebook foram acessados através de sua ferramenta Facebook Audience Insight, uma ferramenta que analisa estatisticamente todos os dados cadastrados pelos usuários na rede e transforma esses dados em informações utilizáveis para o mapeamento de possíveis clientes para produtos e serviços específicos. É uma ferramenta de mapeamento de perfis para o mundo dos negócios. Diz a página que explica a ferramenta cuja chamada é "Seu negócio com o Facebook Audience Insights": "Quanto mais percepções dos clientes você tem, melhor você está equipado para enviar mensagens significativas para eles. Esse é o pensamento por trás do Facebook Audience Insights, uma nova ferramenta desenhada para ajudar os comerciantes a aprender mais sobre seu público-alvo, incluindo informações agregadas sobre geografia, demografia, comportamento de compra e muito mais"4.

Os dados numéricos apontam a diferença significativa entre a quantidade simples de pessoas ativas na página "Feminismo sem demagogia - Oficial" e o total de usuários brasileiros ativos da rede Facebook. Trata-se de uma parcela de $0.9 \%$, mas que é já suficientemente relevante para que a ferramenta produza dados estatísticos sobre esse "agrupamento" (o que não ocorre com páginas com número menor de adeptos). Numericamente, até aqui, podemos considerar o grupo feminista como uma minoria dentro da população e da amostra gerada,

\footnotetext{
${ }^{2}$ https://www.facebook.com/business/news/BR-45-da-populacao-brasileira-acessa-o-Facebook-pelo-menosuma-vez-ao-mes

${ }^{3}$ http://g1.globo.com/tecnologia/noticia/2016/04/internet-chega-pela-1-vez-mais-de-50-das-casas-no-brasilmostra-ibge.html

4 https://www.facebook.com/business/news/audience-insights

\begin{tabular}{|l|l|l|l|l|}
\hline Q Povista Qialectus & Ano 8 & n. 14 & Janeiro - Julho 2019 & p. 213 - 234 \\
\hline
\end{tabular}
}


muito embora o percentual de mulheres usuárias do Facebook no Brasil seja de 53\%. Ou seja, de um total de 48.760 .000 milhões de mulheres ativas do Facebook, cerca de 735.8 Mil são adeptas do "Feminismo sem demagogia - original": 1,5\%. 1,5\% das mulheres que usam o Facebook são "Feministas sem demagogia", ou seja, têm alguma aproximação ou interesse na página feminista com mais adeptos nessa rede.

Mas, qual a diferença de perfil entre esses $1,5 \%$ de mulheres que curtem "Feminismo sem demagogia - Oficial" e as demais? As mulheres pertencentes a esses 1,5\% são mais novas do que as demais: $65 \%$ delas têm entre 18 e 24 anos, enquanto apenas $28.2 \%$ do total de mulheres no Facebook estão nessa faixa etária, e o percentual de mulheres nesse grupo decresce na medida em que a faixa etária aumenta.

As páginas mais curtidas por esses dois grupos podem também nos dar algumas indicações relevantes. As páginas mais curtidas pelas mulheres no Facebook são: $O$ Boticário, Bolsa de Mulher, Risqué, Mary Kay Brasil, Melhor com Saúde, Natura, Lojas Renner, Caio Castro, [Quem disse, Berenice?] e Pantene Brasil - a maioria de empresas de produtos destinados ao público feminino. Já as páginas mais curtidas por aqueles 1,5\% são: Feminismo sem demagogia - Original, Não me Kahlo, Empodere duas mulheres, Diários de uma feminista, Deboas na Revolução, Arquivos Feministas, Feminismo Político, Quebrando o Tabu, Diário Feminista e Desconstruindo conceitos - páginas ligadas ao feminismo ou temas políticos de esquerda. Podemos inferir, então, que o público da página em questão é um público interessado e/ou identificado com questões de esquerda, especialmente as feministas. Aqui nós temos um dado de extrema relevância: embora as mulheres componham o grupo das minorias, em termos de relação de dominação e discriminação, elas não apenas não aderem significativamente ao movimento social em questão, como voltam seus interesses para o consumo de mercadorias que ditam o que é o próprio ser mulher.

É interessante também observar o perfil em relação ao nível de escolaridade. Ambos os grupos são formados, em sua maioria, por mulheres com nível superior, embora dentre as que frequentam o grupo "Feminismo sem demagogia - Oficial", haja um percentual significativamente maior de mulheres com pós-graduação ( $41 \%$ a mais do que grupo geral de mulheres no Facebook, embora represente apenas 5\% das adeptas do grupo). A atividade laboral a qual se dedicam é também significativamente diversa: as mulheres envolvidas com o grupo em questão trabalham $28 \%$ a mais no setor público, $23 \%$ a mais na área de cuidados pessoais, $18 \%$ a mais nas áreas de vendas e artes/entretenimento, $14 \%$ a mais nas áreas de

\begin{tabular}{|l|c|c|c|c|}
\cline { 2 - 4 } & Ano 8 & n. 14 & Janeiro - Julho 2019 & p. $213-234$ \\
\hline
\end{tabular}


educação, serviços sociais e administração, além de 100\% a mais em empregos temporários, comparadas às demais mulheres no Facebook.

Em termos geográficos, as mulheres do grupo "Feminismo sem demagogia - Original", distribuem-se de norte a sul do país, em todas as regiões, mas são proporcionalmente mais numerosas nas cidades de Porto Alegre (48\%), Belém (29\%), Rio de Janeiro (16\%), Recife (14\%), Fortaleza (10\%) e Curitiba (4\%).

Resumidamente, as mulheres adeptas do feminismo sem demagogia, portanto, tendem a ser mais novas do que o grupo de mulheres em geral, a voltar mais seus interesses para outros grupos políticos e feministas e ter um nível de escolaridade mais alto. Elas também trabalham mais em setores como educação, serviço público, artes, esportes e entretenimento, e cuidado pessoal. Parece ser um grupo mais "liberal" (não no sentido econômico) que se destaca da população geral de mulheres. É desse grupo que foi obtido o debate que será analisado a seguir. A página "Feminismo sem demagogia - Original", é definida por sua criadora como

[...] um espaço destinado ao debate a respeito do feminismo pelo viés MARXISTA, e opressão machista/capitalista sobre as mulheres. O espaço está aberto para todas as mulheres, cis e não cis, e homens que queiram compor como aliados a luta e que fique claro, somente homens que queiram compor como aliados, respeitando o protagonismo das mulheres [...] As feministas da esquerda revolucionária Marxista entendem a luta contra o machismo como uma luta inseparável da luta de classes. Entendemos que o feminismo é uma parte importante da luta, pois impulsiona as demandas específicas das mulheres.

Entendemos que é extremamente importante que homens compreendam que a luta das mulheres deve ser apoiada por eles também. Que homens e mulheres devem aliar-se para a luta contra divisão de classes, contra esta elite (que é a verdadeira minoria), que se pôs ao topo do sistema econômico e se beneficia das discriminações sobre as diferenças, inclusive fortalecendo dentro deste cenário a desqualificação da mulher e o elogio à superioridade do homem com a clara intenção de nos separar, de nos pôr em guerra uns contra os outros sem notarmos que, enquanto isso, o inimigo real deita e rola sobre nossas costas cansadas e arqueadas do peso desta opressão que nos impuseram. Só os trabalhadores, homens e mulheres, atuando em conjunto num movimento revolucionário poderão destruir a sociedade de classes e com ela a opressão sobre as mulheres de forma definitiva.

O debate que vou analisar foi realizado a partir do desabafo, do dia 5 de agosto de 2016, de uma moça, estudante secundarista, que foi compartilhado no dia 13 por uma das administradoras na página "Feminismo sem demagogia - Original". Os dados foram colhidos na rede no dia 18 de agosto. Em seu relato a estudante disse:

Moçxs gostaria de relatar a vcs algo horrível q me aconteceu ontem. Sou secundarista na escola Estadual XXXX e ontem um professor proferiu um discurso absurdamente machista. Ele começou comentando na sala com os alunxs q mulher quer ter direitos iguais, mas q não se aposentava com a mesma idade q os homens. Eu respondi dizendo q nós Mulheres temos td o serviço do lar (q por questões culturais e sociais nos é conferido) e não eramos remuneradas, e antes q eu pudesse continuar, ele replicou dizendo q ele limpava a própria casa dele e q se nós

\begin{tabular}{|c|c|c|c|c|}
\hline Revista Dialectus & Ano 8 & n. 14 & Janeiro - Julho 2019 & p. $213-234$ \\
\hline
\end{tabular}




\begin{abstract}
Mulheres limpamos a casa é uma questão de escolha. E quando eu achei q ele não poderia ser mais machista, ele disse q mulher q apanha, apanha porque gosta e q não se separa porque só pensa no pau do homem. Sinceramente ontem foi uns dos piores dias, me senti humilhada, não tenho nem adjetivos para definir meus sentimentos naquele momento. Nunca havia pensado que poderia escutar tamanho machismo no meu ambiente escolar no qual passo maior parte do dia. E que me fz pensar se é realmente um lugar para educar.

\#meuprofessormachista.
\end{abstract}

Até o momento em que os dados foram coletados, esse compartilhamento havia recebido 203 manifestações através dos emoticons: 118 curtidas, 54 carinhas zangadas, 30 carinhas chorando e uma (01) carinha "uau"/espanto. Além disso, foram 34 comentários feitos por 24 pessoas diferentes sobre o relato: 21 mulheres e 03 homens. Uma leitura primeira do debate travado espontaneamente pelos frequentadores da página nos faz perceber a existência de quatro categorias iniciais de manifestação/discurso. 1. Discurso a favor do professor - 06; 2. Discurso contra o professor- $16 ; 3$. Discurso a favor da aluna- $03 ; 4$. Discurso contra a aluna- 02 . Todo o debate gira em torno daquele que teria ou não razão em suas colocações, com a exceção de 03 manifestações que não dizem respeito ao debate em si mesmo.

\title{
1. Discursos a favor do professor
}

“O que ele falou não é machismo, é verdade. Nós deveríamos nos aposentar na mesma idade que homens, não dá pra ser vista como igual me aposentando 5 anos mais cedo, ainda mais eu que tenho empregada doméstica e trabalho menos que o meu marido" (FHR).

"Minha vida pode não ser o padrão da sociedade, mas leis não devem ser feitas de modo que possa injustiçar alguém. Quem deu o direito de mulheres votarem, criaram a lei Maria da Penha e a lei do feminicídio foram todos homens, e daí? Um homem que é pai solteiro vai ter que trabalhar 5 anos a mais mesmo fazendo todas as tarefas de casa sozinho? Devemos ignorar esse tipo de pai só Pq ele é uma minoria? Não né. A lei tem que ser justa” (FHR).

"Não discordo muito dele não... Mulher apanha porque quer sim... Levou uma vez e continua $\mathrm{Pq}$ ? A maioria morre Pq continuou... É um horror! E quando a mulher limpa a casa... $\mathrm{Na}$ boa tem que ensinar desde cedo homem e mulher a fazer isso... Discurso machista para mim seria dizer que isso era obrigação de mulher e ele não falou" (MES).

"Eu acho que homens e mulheres deveriam sim se aposentar na mesma idade. Se até agora as mulheres exigiram seus direitos elas tbm tem que exigir os mesmos deveres ué. E essa desculpa de que mulher faz dupla jornada é desculpa esfarrapada, os filhos ela pode muito bem contratar uma babá, mesma coisa em relação às tarefas domésticas contratar uma diarista ou dividir com o marido/companheira mas se ela não exige isso e faz tudo por conta própria já é

\begin{tabular}{|c|c|c|c|c|}
\cline { 2 - 5 } & Ano 8 & n. 14 & Janeiro - Julho 2019 & p. 213-234 \\
\hline
\end{tabular}


problema dela então, sem falar que não são todas que tem filhos [...] é aí que a gente vê que não são apenas as mulheres que sofrem a "desigualdade"!! Obs: não sou machista antes que me venham chamar disso, apenas acho que todos devem ter o mesmo direito independente do gênero. Se os homens estivessem se aposentando mais cedo q as mulheres eu bateria a boca da mesma forma! Apoio certas coisas em q o feminismo prega mas tbm não sou obrigada a concordar com tudo não" (MPW).

“O professor só disse a verdade!” (LF).

"As mesmas que apanham do marido fazem filas pra visita-los na cadeia... (RP homem).

Podemos notar nos discursos apresentados que, via de regra, toma-se uma experiência individual como signo do geral. Quando FHR diz de sua experiência de mulher que trabalha menos e possui "empregada" e quando a mesma fala de um suposto homem, pai solteiro, que trabalha e faz absolutamente tudo sozinho em sua vida privada e familiar, ela usa de exemplos individuais - o último possivelmente imaginário - para justificar seu posicionamento. Não há qualquer tentativa de relacionar as experiências individuais com os processos sociais e históricos. Isso possivelmente leve LF e FHR a se sentirem à vontade para afirmar a existência de uma "verdade" absoluta que teria sido dita pelo professor e que não deve ser questionada. O discurso da verdade indica o um desconhecimento dos processos históricos; quando FHR diz que os direitos que hoje as mulheres possuem foram-lhe dados/concedidos por homens, ela desconsidera as próprias lutas feministas pelo direito ao voto e pela cidadania. É possível que FHR recorra às suas vivências particulares exatamente na falta de um conhecimento abrangente da história e seus processos, inclusive da história do grupo ao qual pertence. Essa mesma falta parece levar à inversão dos conceitos de injustiça, minoria, e desigualdade, este último trazido por MPW para justificar sua defesa de tempos iguais de aposentadoria para homens e para mulheres, já que toda mulher teria a possibilidade de terceirizar o cuidado dos filhos, da casa e da família, naturalizando o processo de exploração do trabalho. Aqui a mulher que trabalha fora teria não apenas o direito, mas o dever, de operar como funcionária do sistema também ao explorar o trabalho de outra mulher; isso porque MPW não cogita a possibilidade da existência de "um diarista", mesmo porque são as mulheres que historicamente são responsabilizadas pelos cuidados domésticos, remunerados ou não. Nesse sentido, MPW contradiz-se ao indicar o quão livres as mulheres são para escolher realizar esses cuidados. Nota-se que, nos discursos, o sistema de exploração do trabalho torna-se infinito - e a mulher que não fizer parte dele

\begin{tabular}{|l|l|l|l|l|}
\cline { 2 - 4 } Q & Ano 8 & n. 14ta & Janeiro - Julho 2019 & p. 213 - 234 \\
\hline
\end{tabular}


(supostamente por escolha, por não contratar uma funcionária para si) é culpabilizada pela exploração (dupla) que sofre.

Além disso, nos discursos de MPW e de RP, as mulheres também são culpadas, não apenas pela realização do trabalho doméstico, mas pela violência doméstica da qual são vítimas. Todos os processos sociais, históricos e culturais de subjugação moral, violência psicológica e física e os afetos envolvidos - além da dependência afetiva e financeira - são desconsiderados. É interessante notar também que MPW faz questão de indicar sua identificação com as lutas feministas, embora não concorde com todos os seus aspectos (aqui não é possível identificar com quais aspectos ela concorda), e tenta se defender de qualquer julgamento, ao dizer "não sou machista"; mesmo porque assumir esse posicionamento direta e abertamente a levaria a contradições demasiadamente escancaradas para quem assume uma adesão ao feminismo. Afirmar que "todos devem ter o mesmo direito, independente de gênero" é negar direitos a quem historicamente tem a sua existência violada devido exatamente ao gênero, ou mais propriamente ao sexo.

É preciso reconhecer, contudo, que o discurso da igualdade como verdade tem uma dupla possibilidade. A ideologia burguesa o tornou uma verdade, na medida em que cada vez mais ambos os sexos passam a ter formas similares de adequação ao sistema. No entanto, essa mesma ideologia deixa entrever suas contradições ao negar as diferenças constituintes e constitutivas da mulher na sociedade de classes.

Outro aspecto importante que deve ser apontado é que, mesmo fazendo parte de um grupo feminista de posicionamento enfaticamente marxista, não há qualquer questionamento dos processos de exploração do trabalho nesse sistema de produção, e os discursos a favor do professor parecem envolver uma "guerra entre os sexos", que a descrição do grupo já havia indicado como problemática. Passa-se ao largo de questionar a real necessidade de um tempo de trabalho tão longo e exaustivo.

\section{Discursos contra o professor}

"Eu iria direto para a diretoria, até onde sei escola não é para ensinar machismo" (TTD). "FHR, essa é boa na interpretação de texto! E ainda defende os homens que batem nas mulheres! Bolsiminion de merda!” (TDS).

"Se fosse eu, eu batia boca com ele até ele se calar e ainda gravava tudo só pra expor esse infeliz, há algum tempo atrás um professor meu disse em uma sala cheia de mulheres que 'homem morria mais $\mathrm{Pq}$ era mais corajoso do que mulher, e que também se arriscava mais em

\begin{tabular}{|c|c|c|c|c|}
\cline { 2 - 5 } Q Q Dialectus & Ano 8 & n. 14 & Janeiro - Julho 2019 & p. 213-234 \\
\hline
\end{tabular}


algumas profissões", ele deu o exemplo de que se o pneu do carro de uma mulher furar em uma estrada enquanto tiver chovendo ela não sai do carro para não borrar a maquiagem, eu como não fico calada disse que uma mulher não sai do carro para trocar pneu $\mathrm{Pq}$ não somos irresponsáveis e imprudentes que nem um homem, e eu estava sercada de mulheres e elas olharam para o professor e começaram a sorrir, e ele ficou envergonhado se virou e continuou a aula e nunca mais tocou no assunto!" (JC).

“Gente, não deixem isso acontecer, se os professores de vocês estão falando qualquer preconceito juntem a sala e levem direto para a secretaria, pode não dar em nada, por enquanto, mas se outras salas continuarem a reclamar a pessoa acaba sendo tirada de lá" (DG - homem).

"Que absurdo, joga o nome dele na net. Infelizmente algumas pessoas aprendem pelo amor, outras só passando vergonha mesmo" (HF).

"São canalhas que tem inveja de mulher Pq queriam na verdade ser uma, já falo logo para nascer de novo ou ir em busca da realização do sonho da vida deles que completará as suas vidas, ou seja, ir atrás de uma cirurgia de mudança de sexo. Daí param de ter inveja e raiva de mulher. Mulheres têm bem mais problemas de saúde que os homens, a droga da TPM e menstruação e menopausa que acabam com as mulheres, todo o revertério hormonal e desgastes na gravidez..." (EJS).

“A mulherada tem que largar de ser besta, principalmente se for casada com um lixo invejoso desse que na verdade queria ser mulher e não gosta de ser homem. Para de se sobrecarregarem e dividam as obrigações. É isso mesmo, hoje em dia os homens como esse cara querem mulheres para os sustentar, se você faz todo o serviço doméstico faz o homem pagar todas as despesas. Mas não, tem mulher burra que além da jornada dupla, cuidar da casa, só nas costas dela, ainda divide as despesas, uma coisa ou outra vc tem que escolher. Senão um boa vida desse ainda vai querer sua aposentadoria para ele" (EJS).

Os discursos que se colocam contrários à fala e ao posicionamento do professor parecem sofrer da mesma falta de análise histórica que sofrem os discursos analisados anteriormente, na categoria que seria, a priori, oposta à esta. No entanto, tanto a forma, quanto o conteúdo (digase de passagem, de caráter absolutamente vazio), parecem ser bastante semelhantes. No último trecho apresentado, EJS faz coro com o discurso de culpabilização da mulher ao dizer que a mulher que trabalha fora e cuida da casa é "burra" e o homem "esperto" vai se aproveitar de alguém assim, necessária e naturalmente. Aqui, a figura do homem também aparece naturalizada e fora de seu contexto social e cultural. Se as mulheres são chamadas de "burras", os homens são chamados de "canalhas" na postagem anterior, onde o machismo é encarado

\begin{tabular}{|c|c|c|c|c|}
\hline Qonista Dialectus & Ano 8 & n. 14 & Janeiro - Julho 2019 & p. $213-234$ \\
\hline
\end{tabular}


como "desejo de ser mulher", em uma tentativa rasteira de psicologizar esse fenômeno histórico de dominação do outro e de si mesmo. Nesse sentido, também são naturalizados os chamados "problemas de saúde da mulher", sem que sequer se indique que as formas de vida o que inclui o mundo do trabalho - têm influência direta nos modos de manifestação das alterações hormonais que fazem parte do ciclo reprodutivo feminino: alimentação, exposição a hormônios, situações geradoras de estresse e ansiedade etc.

O que surpreende aqui é que, além da culpabilização da mulher, transparece nesse caso um discurso de ódio voltado para a própria mulher que se posicionou de modo diverso: FHR foi chamada por TDS de "Bolsominion", em uma clara alusão ao modo com que são chamadas, de modo estereotipado e a partir de uma figura do entretenimento, pessoas que são favoráveis às ideias de um determinado político brasileiro de direita. Essa linguagem da estereotipia nos remete diretamente ao pensamento do ticket já caracterizado por Horkheimer e Adorno (1985) em "Elementos do antisemitismo" e por Adorno e colaboradores (1969) na personalidade autoritária. No ticket, o pensamento é bloqueado e substituído por clichês que servem de apelos orientadores num mundo que não se compreende; não há espaço para abertura ao outro e possibilidade de vê-lo como alguém além dos estereótipos através dos quais se faz uma primeira e derradeira leitura. Interessante é que a própria analogia "bolsominions" faz referência à essa estereotipia no outro. Essa falta de abertura nos faz desistir de qualquer possibilidade de diálogo, daí a necessidade sempre colocada de busca por uma autoridade que seja capaz, em algum momento (agora ou depois), de solucionar a questão: expulsar o outro, banir sua circulação do mesmo espaço que circulo e, ao mesmo tempo, me proteger e manter na situação de menoridade em que permaneço. Por isso, TTD e DG se posicionam de modo a indicar a necessidade de sempre "denunciar" o caso, seja na diretoria, seja na secretaria, não para que o diálogo possa acontecer com a participação de mais atores, mas para que a pessoa "acabe sendo tirada de lá".

O princípio de eliminação do outro também opera através de um determinado posicionamento de "justiceiro": à falta de diálogo responde-se com a exposição do outro nas redes sociais, como numa espécie de vingança. O sujeito "machista" deve pagar a humilhação que faz às mulheres com sua própria humilhação, prolongando e reproduzindo um ciclo eterno de subjugação, ridicularização e dominação típicos do estado de coisas atual. Mais uma vez, a "crítica" realizada pelos interlocutores desse diálogo sequer toca na problemática da relação entre os sexos na sociedade de classes. O que temos aqui é uma espécie de identificação com o agressor - mecanismo de defesa descrito por Anna Freud e bastante referido por Adorno em

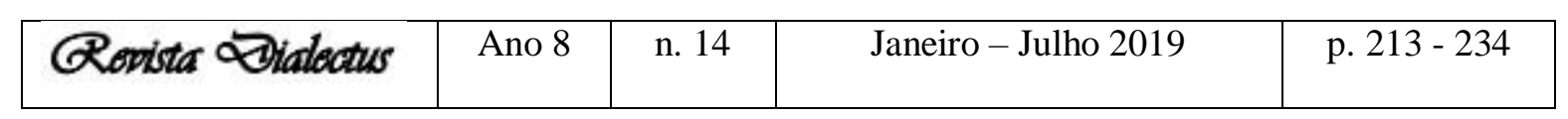


seus estudos sobre o preconceito - que se faz notar de modo eficaz na forma com que os oprimidos se atacam mutuamente e esquecem-se de se posicionar contrariamente frente ao que de fato é a causa da opressão. Esse mesmo mecanismo foi descrito por Leo Lowenthal nos campos de concentração nazistas.

\section{Discursos contra a aluna}

"Estuda, se forma, trabalhe e não se relacione com um homem que pense como ele, ué. Seja empoderada, querida! Saia desse mundinho do jardim da infância, onde todo mundo só fala coisinha bonitinha e coisa que nos agrada. Esteja preparada para a vida, porque durante toda ela, você vai ver pessoas que te enojam e pessoas que dizem coisas que você não gosta. Eu já tive que ouvir professor meu pregando comunismo... Já tive que ouvir professor dizendo que existe mulher de testículos... Já tive que ouvir professor meu defendendo Dilma... Nem por isso vim me vitimizar" (LF).

"Então, eu me enojo de professor que fica em sala de aula passando SUA OPINIÃO, SEU PONTO DE VISTA como verdade absoluta aos alunos que estão lá para aprender. Dessa forma, esses alunos não aprendem a questionar, pois não conhecem todos os lados e, sim o que o professor quer que conheçam. Nem por isso me vitimizando e dizendo que sou vítima oprimida" (LF).

Essa frequentadora da página se manifestou atacando diretamente a estudante autora do desabafo, mesmo que não tenha sido ela quem compartilhou seu texto nesse grupo. LF "aconselhou" a estudante a se "empoderar" através do estudo, da formação e do trabalho, para não precisar se relacionar com homens como o "professor" denunciado. Tal empoderamento é indicativo de uma liberdade que seria conquistada através do dinheiro, da possibilidade de aumento de seu poder aquisitivo. "Esteja preparada para a vida", diz LF, aconselhando a estudante a operar certo "princípio de realidade", de "adaptação" ao que existe. Além de pregar o empoderamento através de um discurso em que se coloca em posição de superioridade, LF chama a estudante de infantil e não aprofunda a questão, tomando a ideia de infantil como inadequada, quando, de outro modo, o infantil poderia muito bem nos indicar possibilidades impensadas pela visão já adaptada e a imaginação já bloqueada do adulto.

Em sua segunda postagem, ela deixa claro que compreendeu o posicionamento do professor como uma "questão de opinião", de "ponto de vista" e, portanto, legítimo de ser colocado como qualquer outra opinião política - embora ela diga sentir 'nojo' de professor que manifesta seus posicionamentos em sala de aula, como se os alunos não tivessem outros

\begin{tabular}{|l|c|c|c|c|}
\cline { 2 - 5 } & Ano 8 & n. 14 & Janeiro - Julho 2019 & p. $213-234$ \\
\hline
\end{tabular}


momentos em que podem experienciar os diversos posicionamentos existentes. É claro que a profissão de ensinar garante ao professor certo espaço de autoridade, mas lidar com a autoridade faz também parte do processo formativo, inclusive quando se faz necessário questionar preconceitos arraigados.

\section{Discursos a favor da aluna}

"trabalhe e não se relacione com homem que pense como ele". Essa foi triste! O que uma coisa tem haver com a outra? Não estamos aqui para aceitar esse tipo de coisa, nada impede de continuarmos a termos professores assim em mestrado e doutorado e patrão assim. Na vida nem sempre dá pra escolher com quem se relacionar. Temos que combater esse tipo de comportamento sim, e não fingir que não está ouvindo. Ouvir professor defendendo Dilma? De que isso importa? Ele não tem direito a posicionamento político? Por que uma pessoa iria se vitimizar por ter um professor defendendo Dilma (não me sentiria vítima de nada se um professor defendesse o Aecio, apenas pensaria que ele tem problemas)? Oxe! (AC).

"essa aí deve ser apoiadora da "escola sem partido", no qual o professor não pode mais falar sobre política na sala de aula, exatamente para manter as coisas como estão. Ah esses meninas passivas que acham que o mundo vai mudar só com contemplação... Ninguém é obrigada a aceitar nada não, moça, inclusive você podia ter debatido com seu professor ao invés de ficar fazendo cara feia e reclamando no facebook. Ninguém está se vitimizando aqui, o espaço é pra desabafar mesmo" (DAC).

"A minha resposta é sempre eu não me importo em me aposentar mais tarde, mas quero igualdade salarial" (PRA).

Essas manifestações de defesa da estudante (as duas primeiras), foram em resposta aos ataques realizados por LF. AC questionou exatamente a suposta relação entre trabalho e liberdade, denunciando que a independência financeira da mulher não está diretamente relacionada com a conquista de sua liberdade. Por isso, o comportamento machista deve ser combatido. AC também problematiza a diferença entre um posicionamento político (onde se expressa diretamente a respeito de uma política formal de estado) e um posicionamento preconceituoso que enquadra e cerceia o outro e sua existência. Já DAC responde LF utilizandose de expressões tendenciosas, na tentativa de desabonar a interlocutora, ao invés de manter o diálogo sustentado por argumentos críticos: ela julga que LF seria adepta da proposta de "escola sem partido", e a chama de "passiva". Contudo, LF não se posiciona de forma passiva, ao contrário, seu conselho de empoderamento é totalmente ativo - o que poderia ser questionado

\begin{tabular}{|c|c|c|c|c|}
\hline Qonista Dialectus & Ano 8 & n. 14 & Janeiro - Julho 2019 & p. $213-234$ \\
\hline
\end{tabular}


é a possibilidade que ele tem de, de fato, operar transformações nessa sociedade ao se realizar do mesmo modo que o sistema operante. Em seus textos sobre Educação e Emancipação, Adorno (1995) aponta esse como um dos problemas da emancipação: a organização em que vivemos e a ideologia dominantes opera o obscurecimento das consciências pelo existente e a adaptação é exigida num movimento contínuo pela realidade que produz "pessoas ajustadas". PRA, ao se colocar a favor da estudante, simplesmente compartilha com as demais que para ela o importante é conseguir igualdade salarial. Novamente os discursos passam ao largo do questionamento da sociedade - o que nos faz lembrar do conceito marcuseano de sociedade unidimensional e do fechamento do universo do discurso mesmo dentre aqueles que se propõem a estar na luta pela libertação de grupos sociais historicamente oprimidos.

\section{Considerações finais}

Esse pequeno debate nos traz uma fotografia de um momento específico naquele grupo. Ele parece, inicialmente, contradizer a ideia de que exista qualquer possibilidade emancipatória advinda das minorias e suas lutas, na medida em que fica clara a contradição entre a ideia de libertação, base da luta feminista, e o modo estereotipado e rígido com que o debate se estabelece. A ideia, contudo, aqui, não é traçar um perfil das chamadas "massas" no intuito de desabonar seus movimentos com pretensões libertárias - o que ocorre com bastante frequência nos estudos sobre os movimentos populares desde Le Bon. Apontar pura e simplesmente a irracionalidade no interior dos movimentos revolucionários serve à manutenção do estado de coisas atual. É exatamente nesse sentido que os movimentos de direita traçam suas críticas aos movimentos de esquerda: apontam suas contradições na tentativa de arruinar seu potencial negativo. Bastante significativa é a última postagem feita na página "fake" criada para desabonar esse movimento. Existe uma página de mesmo nome, com cerca de 4 mil curtidas, criada e movimentada por opositores ao movimento feminista. Ali, um dos administradores da página postou, no dia 30 de março:

"É com muita insatisfação que venho as comunicar sobre algo muito importante. No meio da militância feminista sofremos opressões por várias partes, isso é, desde a sociedade patriarcal, até as "mulheres" que não aceitam o feminismo, até mesmo das que te chamam de "mana" e pelas costas te fuzilam. Sem contar das que já não buscam por igualdade, mas sim pelo caos, deixando claro a misandria, o ódio puro aos homens. E é por este meio que comunico à vocês sobre o FIM da militância feminista, pelo motivo de que, até mesmo no próprio meio há opressões, sendo impossível de militar desta forma, com tanta falsidade e traição. São

\begin{tabular}{|l|c|c|c|c|}
\cline { 2 - 4 } & Ano 8 & n. 14 & Janeiro - Julho 2019 & p. $213-234$ \\
\hline
\end{tabular}


impostos padrões no feminismo (por quem diz fugir de padrões), e não aceitamos hipocrisias. Então manas, prestem bem atenção se é esse meio que vocês querem mesmo seguir, e cuidado com quem diz estar do seu lado, pois eu jamais vi um movimento tão falso, sujo e hipócrita como este! Aqui deixo essa mensagem de alerta para vocês, e anunciando o fim do que já deveria ter acabado, ou do que jamais existiu, a luta pela igualdade, o FEMINISMO!"

Esse tipo de argumento é encontrado com bastante frequência nos discursos daqueles que se colocam em posição conservadora. No estudo sobre a personalidade autoritária e hoje na política brasileira - para pegar um exemplo bastante próximo - as críticas feitas à democracia são utilizadas como justificativa para abolir a democracia e não para construí-la processualmente por meio da autorreflexão e da autocrítica. É como se os erros cometidos na democracia minassem toda e qualquer possibilidade de sua realização. Isso é uma falácia do pensamento antidemocrático.

O próprio fato de que, hoje, as pessoas têm se reunido cada vez mais em torno de temas específicos em prol da libertação nos indica a existência de possibilidades que devem ser exploradas e que não existiram em outros momentos históricos. E os caminhos para tal libertação deve ser traçado a partir do já existente.

Não podemos acreditar ingenuamente, contudo, que o potencial negativo, que a teoria tão eficazmente aponta existir nas minorias, encontrará livremente na história seu momento de realização. Teríamos nesse caso uma dialética “positivisada”. É preciso encarar com maturidade as contradições da existência aqui e agora. Não devemos fechar os olhos para os dados empíricos que devem ser analisados criticamente para a compreensão do presente e das possibilidades do futuro. No prefácio ao livro que relata a pesquisa de Adorno e colaboradores sobre o preconceito, Horkheimer nos fala do receio de muitos teóricos críticos de que as análises realizadas ali pudessem ser utilizadas contra as próprias minorias, para bloquear os processos de transformação da sociedade. Mas é ele mesmo quem ali nos alerta que esse é um medo que deve ser superado: uma análise crítica, sistemática e sincera do existente precisa enfrentar seus próprios fantasmas. A tomada de consciência de seu próprio engodo é condição necessária para a efetividade da luta pela libertação - e nisso a pesquisa empírica criticamente orientada tem um papel de extrema relevância. O reconhecimento de nossos determinantes, contradições e situação no mundo atual pode nos ajudar a liberar aquele potencial negativo que hoje encontra ainda poucas brechas de realização.

“A esperança de que o horror terreno não tenha a última palavra é, sem dúvida, um desejo não científico" (Horkheimer, 2008, p. 26), escreveu Horkheimer no prefácio de $A$

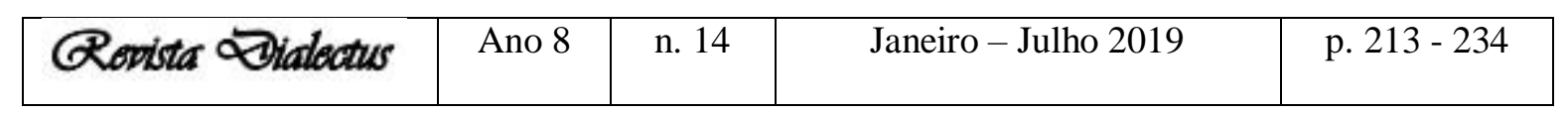


imaginação dialética, de Martin Jay. Que possamos somar forças, na luta pela liberdade, ao trabalho realizado por Adorno, Marcuse e outros pesquisadores da Escola de Frankfurt - que realizemos pesquisas que ainda não têm lugar na universidade "com a convicção de que formular o negativo" é "mais importante do que construir carreiras acadêmicas".

A primeira coisa que temos que fazer, como intelectuais, professores, estudantes de Teoria Crítica, é questionar nosso estranhamento frente às formas "desconhecidas" de saber e de existência, aquelas que não entendemos, que não alcançamos por conta de nossos próprios padrões de pensamento. Finalizo com a pergunta: Quem ousará atingir o não conceitual?

\section{Referências:}

ADORNO, T.W. Dialética negativa. Trad. Marco Antonio Casanova. Rio de Janeiro: Jorge Zahar Ed., 2009.

Lectures on negative dialectics. Trad. Rodney Livingstone. Cambridge/Malden: Polity Press, 2010.

. et al. The authoritarian personality. New York: WW Norton, 1969.

HOKRHEIMER, M. Towards a new manifesto. London/New York: Verso, 2011.

CHAVES, L. G. M. Minorias e seu estudo no Brasil. Revista de Ciências Sociais, Fortaleza, v. 1, n. 1, p. 149- 168, 1971. Disponível em: http://www.repositorio.ufc.br/handle/riufc/4487. Acesso em agosto de 2016.

DAVIS, A. Y. Freedom is a constant struggle: Ferguson, Palestine and the foundations of a movement. Chicago: Haymarket Books, 2016.

HORKHEIMER, M. Ocaso. Barcelona: Anthropos, 1986.

ADORNO, T.W. Dialética do esclarecimento: fragmentos filosóficos. Rio de Janeiro: Jorge Zahar, 1985.

JAY, M. A imaginação dialética: história da Escola de Frankfurt e do Instituo de Pesquisas Sociais 1923-1950. Rio de Janeiro: Contraponto, 2008.

LACAN, J. O mestre e a histérica. In: Lacan, J. O seminário, livro 7: o avesso da psicanálise 1969-1970. Rio de Janeiro: Zahar, 1992.

. O homem e a mulher. In: Lacan, J. O seminário, livro 18: de um discurso que não fosse semblante. (1971). Rio de Janeiro: Zahar, 2009.

RIBAS, G. C. Considerações sobre a evolução filogenética do sistema nervoso, o comportamento e a emergência da consciência. Rev. Bras. Psiquiatr. São Paulo, v.28, n.4, p.326-338, Dec. 2006.

\begin{tabular}{|l|l|l|l|l|}
\cline { 2 - 4 } & Ano 8 & n. 14 & Janeiro - Julho 2019 & p. $213-234$ \\
\hline
\end{tabular}


SARTRE, J.P. Anti-semite and jew. New York: Schocker Books, 1966.

\begin{tabular}{|l|l|l|l|l|}
\hline Q & Ano 8 & n. 14 & Janeiro - Julho 2019 & p. 213 - 234 \\
\hline
\end{tabular}

